\title{
IMPURITY PHENOMENA IN PHYSICS AND CHEMISTRY
}

\begin{abstract}
A THREE - DAY symposium on "Impurity Phenomena" was held at the Knoll's Research Laboratory of the General Electric Co., Schenectady, during June 16-18, arranged by the Division of Physical and Inorganic Chemistry and the Eastern New York Section of the American Chemical Society in conjunction with the Division of Solid State Physics of the American Physical Society. About three hundred persons attended the symposium, and it proved a very successful meeting-ground for chemists and physicists active in a field in which contributions of both groups have been significant.

The first session, under the chairmanship of Dr. F. E. Williams (General Electric Research Laboratory), dealt with general aspects of impurity phenomena. Prof. F. Seitz (University of Illinois) set the stage for the symposium by reviewing the range of crystal imperfections. From such a point of view, imperfections in a perfect crystal include lattice vibrations or phonons; free electrons and holes; excitons (a neutral electron-hole combination); vacancies at lattice sites and interstitial ions or atoms in the lattice ; $F$-centres ; foreign or impurity atoms or ions ; and dislocations: Light interacting with such a crystal is treated in terms of photon impurities in the lattice. Prof. Seitz went on to say that the significant advance of recent years has been in the disentangling of these separate imperfections and in showing their inter-relationships. Thus $F$-centre formation can be shown to be a result of the interaction of several imperfections-dislocations associating to form ion vacancies, free electrons being produced and then being trapped at the negative ion vacancies. The following paper, by Prof. C. Wagner (Massachusetts Institute of Technology), dealt with the role of lattice defects for solubility problems in ionic crystals and stressed the similarities with solubility problems of ideal and non-ideal aqueous solutions. Among the problems cited was the decrease in the solubility of silver sulphide in zinc sulphide in the presence of cuprous sulphide. In general, the solubility of a solute 2 in the solvent crystal 1 will be decreased by presence of a solute 3 if both solutes have either a greater-or a smaller cation/anion ratio than the solvent, and thus dissolution of solutes 2 and 3 results in the formation of the same type of defect, either interstitial ions or vacancies. The last paper of the general session was entitled "Evidences of Crystalline Imperfections in Nuclear Magnetism" and was presented by Prof. R. V. Pound (Harvard University). Nuclear paramagnetic resonance has become a tool for the study of the solid state, and some effects were described. The relaxation times measured can indicate the strength of the heat contacts between the spin system and the lattice, and these are modified in the presence of impurities. Paramagnetism associated with lattice constituents was discussed, and the presence of dislocations and their density may also be investigated for 'perfect' and 'work-hardened' crystals.
\end{abstract}

The second session, under the chairmanship of Dr. P. Pringsheim (Argonne National Laboratory), dealt with the coloration of solids by impurities. Dr. J. H. Schulman (Naval Research Laboratory) indicated how impurities can influence markedly the colorations produced by ionizing radiations on solids. The impurities may change the number of crystal defects due to mis-match in ion size or polarization properties. They may change the concentrations of negative and positive ion vacancies due to electrostatic charge differences between the impurities and host crystal constituents, and they may act as traps for electrons and holes. Since the concentrations required for such effects may be very small, there is a field of investigation unfolding to disentangle the effects mentioned from those associated with host crystals of ultra-purity. Prof. W. A. Weyl (Pennsylvania State College) read a paper on metals in the atomic state in glasses, contrasting with their behaviour in solids. The coloration of alkali halides by the presence of colloidal metal was described by A. B. Scott, W. A. Smith and M. A. Thompson (Oregon State College). Alkali halides containing excess alkali metal, on moderate heating, develop absorption bands due to colloidal metal of estimated particle size 10-50 A. After extended heat treatment, the particle size becomes increased, and scattering of the light then occurs. J. J. Markham (Johns Hopkins University) closed the session with a synthesis of some of the properties of colour centres. He discussed the interaction of colour centres with their environment and separated two classes of interactions-the macroscopic, which affect the rates at which bands are formed during irradiation and affect the bleaching rates both in the light and in dark, and the microscopic, which affect the shape of the band and the bleaching properties at very low temperatures. The question of whether there exists more than one type of $F$-centre depending on the method of preparation still remains open.

The third session, with Dr. H. W. Leverenz (R.C.A. Laboratories) as chairman, dealt with activators in luminescent crystals. Prof. R. Ward (University of Connecticut) spoke on the chemistry of phosphors and on the increasing necessity for ultra-high purity in the preparation of the chemicals. $\mathrm{He}$ discussed certain luminescent systems such as zinc sulphide/copper in which the concentration of copper impurity markedly affects the colour of the luminescence. The need for inclusion of compensating ions to satisfy electrical neutrality was emphasized, and he ended with a discussion of recent work on the luminescence of materials with perovskite structure. Dr. C. C. Klick (Naval Research Laboratory) spoke on emission and absorption associated with luminescent centres at low temperatures. The main features at low temperatures are: that the bands remain broad; the emission and absorption band-widths vary as the square root of the temperature at high temperature but vary at a lesser rate and approach a constant value at low temperatures; and some systems show an emission composed of equally spaced 'lines'. Certain of these features could be explained by treating the luminescent centre as a one-dimensional harmonic oscillator. Vibrational frequencies in the range $10^{12}-10^{13} \mathrm{c} / \mathrm{s}$. are obtained on the basis of such a model. Dr. D. L. Dexter (University of Rochester) spoke on the theory of sensitized luminescence in solids. To obtain sensitized luminescence one adds to the host crystal two sets of activators. One, the sensitizer, possesses strongly allowed optical transitions and absorbs the incident radiation, the other, the activator, has a forbidden transition; and the two are chosen so that 
the emission band of the sensitizer overlaps the absorption band of the activator. There is then a radiationless transfer of energy from the sensitizer to the activator. The extent of the sensitized region surrounding each sensitizing centre was indicated as about thirty lattice sites with a general increase in sensitivity in the region of a thousand. The theory of the luminescence of impurity-activated ionic crystals was discussed by Dr. F. E. Williams (General Electric Research Laboratory), who indicated how refinements to the recent theory of the luminescence of thallium-activated potassium chloride improve agreement between theory and experiment. The angular dependence of the wave function of the excited state affects the luminescence peak-shape. An evaluation of the first-order perturbation of the energies of the activation ions by the crystal field indicates that it is appreciably different for the ground and excited states, thus altering the position of the emission and absorption peaks. Dr. R. H. Bube (R.C.A. Laboratories) gave a general paper on traps and trapping processes and their importance for luminescence theory, particularly in affecting frequence response. Traps due to host crystal imperfections and due to the presence of impurities have been separated and studied for sulphide and silicate phosphors.

The next session was devoted to the photographic process. In his introduction, the chairman, Dr. J. A. Leermachers (Kodak Research Laboratories) indicated the scope of the photographic process, its dependence on rate processes and the problems connected with the primitive sensitivity and the superimposed chemical effects. Dr. F. Urbach (Kodak Research Laboratories) presented a paper, read by Mr. D. Pearlman, on some effects of inorganic impurities on silver halide crystals. Slight traces of alkaline earth metals in silver bromide produce luminescence at $77^{\circ} \mathrm{K}$. with long afterglow. In addition, very slight amounts of nickel and gold in silver bromide have been found to produce marked effects. Dr. G. W. Luckey (Kodak Research Laboratories) discussed recent measurements performed on the vacuum photolysis of silver bromide. The pressure of photolytic bromine was measured for slabs, crystals and evaporated films and the quantum yield-that is, the number of bromine atoms produced per quantum of light absorbed-was found to increase with decreasing wave-length. The results showed vacuum to be a good halogen acceptor, and the quantum yield is near unity when the concentration of electron traps is high. For thick specimens the decomposition that produced measurable quantities of bromine occurred in a surface layer of the crystals of thickness approximately 0.3 micron. Dr. W. West (Kodak Research Laboratories) read a paper on the effect of impurities on the optical sensitization of the photographic emulsion. It is well known that the general level of sensitivity of silver halide photographic emulsions may be increased by the presence of chemical impurities on the surface, as for example sulphur, which may be introduced during the emulsionripening process. There are also other sensitizersfor example, certain dyes-which confer sensitivity in the long wave-length region and the general level of activity of which is governed by the presence of slight traces of additional impurities which may increase sensitivity (super-sensitizers) or decrease sensitivity (anti-sensitizers). A general mechanism associated with these processes was presented. The session closed with a paper by F. W. H. Mueller, H.
Hoerlin and E. T. Larson (Ansco Division) describing the sensitization of $\mathrm{X}$-ray emulsions by very small quantities of a divalent salt such as lead or cadmium bromide.

"Analysis for Trace Impurities" was the subject of the fifth session under the chairmanship of Prof. W. D. Cooke (Cornell University). Dr. M. G. Inghram (University of Chicago) outlined the use of the mass spectrometer for trace element determination with particular emphasis on the isotopic dilution method. Analysis for trace impurities by neutron activation was described by W. A. Brooksbank, G. W. Leddicoto and H. A. Mahlman (Oak Ridge National Laboratory), and the sensitivity of the method in several instances was cited. Details were described of the recently inaugurated public service whereby specimens may be submitted for analysis at the Oak Ridge National Laboratory. A second paper, by W. A. Brooksbank and $G$. W. Leddicote, described procedures for separating out trace impurities by ion-exchange methods for use in conjunction with the neutron-activation techniques. The combination provides an extremely sensitive and specific method for the determination of small quantities of the rare earths and alkali elements in the presence of each other. Dr. I. Strock (Sylvania) followed with a paper on the extension of the sensitivity of emission spectroscopy both by physical means within the light source and by means external to the source. The methods have been used for impurity estimation in germanium in the $10^{-5}$ to $10^{-7}$ weight per cent range- that is, 1 part impurity in $10^{7}-10^{\circ}$ atoms. C. A. Streuli and W. D. Cooke (Cornell University) discussed the application of a polarized mercury-pool electrode to polarography, indicating its advantages coupled with greater sensitivity compared with the dropping-mercury electrode. Polarograms for several metals were shown with a sensitivity of about $20 \times 10^{-8} \mathrm{gm} . / \mathrm{ml}$.

The final session, under the chairmanship of Dr. A. H. White (Bell Telephone Laboratories), wes devoted to papers discussing the role of impurities in semi-conductors and transistors. The equilibrium thermochemistry of solid and liquid alloys of germanium and silicon was discussed by C. D. Thurmond and J. D. Struthers (Bell Telephone Laboratories). The solubilities of antimony and copper in germanium were determined. Dr. R. N. Hall (General Electric Research Laboratory) discussed the segregation of impurities during the growth of germanium and silicon crystals. By a radiographic technique this segregation was observed and its dependence on rategrowth and crystal orientation determined. Since this dependence is generally much greater for donor impurities than it is for acceptors, it makes possible the growth of crystals containing large numbers of $p-n$ junctions. H. M. James and A. S. Ginsberg (Purdue University) read a theoretical paper on the effects of impurity atoms on the band structure of alloys and semi-conductors on the basis of a one-dimensional alloy or crystal. The sharply defined impurity band for a crystal with the regularly placed impurities becomes replaced by a broadened region of high energy-level density when the impurities are randomly arranged. E. Burstein, E. E. Bell and J. W. Davisson (Naval Research Laboratory) and M. Lax (Syracuse University) discussed some optical investigations of impurity-levels in silicon at the temperature of liquid helium. Optical absorption by neutral impurities may involve two things: photo-ionization of boundcharge carriers, which is accompanied by photoconductivity ; and optical excitation of bound-charge 
carriers from the ground-state to higher energy-states which appears as relatively narrow bands at wavelengths beyond the photo-ionization limit. Such transitions are observed in boron-doped specimens at $28 \cdot 7,31 \cdot 2$ and $36 \cdot 0$ microns, which are attributed to $1 s-4 p, 1 s-3 p$ and $1 s-2 p$ transitions respectively. J. A. Burton, G. W. Hull, F. J. Morin and J. C. Severiens (Bell Telephone Laboratories) described the effects of nickel and copper impurities on increasing the rate of recombination of holes and electrons in germanium. The dependence of lifetime on resistivity at room temperature is consistent with the ShockleyRead-Hall theory of recombination at traps near the middle of the forbidden band. The capture crosssection of these traps for holes and electrons were estimated. The final paper, by Dr. S. R. Morrison (University of Illinois), described measurements on the changes of surface conductivity of germanium with ambient atmosphere, in which the changes of conductivity were correlated with changes in the space charge layer at the free surface of the semi-conductor.

The majority of the papers read at the meeting will be published in the November issue of the Journal of Physical Chemistry. W. GRATTIDGE

\section{INSTITUTE FOR THE ENCOURAGEMENT OF SCIENTIFIC RESEARCH AND AGRICULTURE, BRUSSELS REPORT FOR 1952}

\footnotetext{
$\mathrm{T}$ $\mathrm{HE}$ annual report for 1952 of the Institute for the Encouragement of Scientific Research and Agriculture, Brussels*, records forty-one grants made during the year, totalling $99,894,670$ Belgian francs. Of this sum, 16,870,000 francs went to the Committee for Mapping the Soil and Vegetation of Belgium for systematic studies of the pedological character of the soils and completing the pedological map. A grant of 8.19 million francs went to the Committee for the Study of the Disease and Nutrition of Cattle, partly for research on trichosomiasis and brucellosis and partly for investigations on nutrition. The National Centre for Grass and Fodder Research received $7 \cdot 35$ million francs for research on the rational and intensive exploitation of grass in Belgium, and the National Centre for Metallurgical Research 7.18 million francs in support of its programme of research on the determination of gas and the influence of the presence of gas in metals, the determination of occlusions in steel, spectral analysis and metallurgical physics. These investigations have included comparative studies on the determination of nitrogen in ferrous alloys, cast iron and special steels, the deoxidizing action of silicon, aluminium, silicoaluminium, silico-calcium and magnesium, and microkinematographic studies of fracture by bending. The National Committee for the Study of Fruit Culture received a grant of $5,632,250$ francs in support of a programme of work bearing on the rational development of orchards, for researches relating to soils and manures, plant investigations, including systematic studies on plums and apples, cytological research, and researches on fruit pathology. A grant of 4.45 million francs went to the Cornmittee for the

* Institut pour l'Enoouragement de la Recherche Scientiflque dans 1'Industrie et l'Agriculture. Rapport Annuel, Exerclce 1952. Pp. 175. (Brussels, 1953.)
}

Scientific and Technical Study of Milk and its Products for work in this field, including the preservation of milk, the changes occurring in butter on storage in refrigerators, the microbial floral and chemical composition of different makes of cheese, and studies on the preparation of acidified milks such as yoghourt. $3 \cdot 81$ million francs to the Technical and Scientific Centre of the Belgian Glass Industry were for the continuation of investigations on the annealing of glass, on the physical and chemical properties of different glasses and on the manufacture of mirrors.

The Centre for Studies and Research into Hydroponics received $2,525,000$ francs for its investigations on the behaviour of certain agricultural and horticultural plants on cultivation in mineral substrata and on the mineral nutrition of vegetables; 2,312,500 francs went to the Belgian Centre for the Study and Documentation of Water for research on water treatment, on rust and corrosion and on effluents; and $\mathbf{2 , 2 7 6 , 5 0 0 ~ f r a n c s ~ t o ~ t h e ~ C o m m i t t e e ~ f o r ~ t h e ~ S t u d y ~ o f ~}$ Metallic Creep at Ordinary Temperatures for further work on creep in hardened steel. The Centre for the Study of High Polymers received 2,262,000 francs for chemical and physico-chemical investigations on high polymers, and the Committee for the Study of Metallic Creep at High Temperatures 2,088,000 francs for investigations on the creep of steel above $575^{\circ} \mathrm{C}$. ; $2,040,000$ francs were granted to the Committee for the Study of Organic Matter in Belgian Soils for investigations on the degradation of certain soils through loss of structure, and 1,892,000 francs for investigations into animal and vegetable physiology using the radioactive isotope technique. Research on the machinability of steel received a grant of $1,849,000$ francs; 1,781,300 francs went to the Centre for Scientific and Technical Research of the Metal Industry for casting research ; 1.7 million francs for pathological and genetical research on the potato; $1,460,000$ francs for corrosion research, including cathodic protection and the study of descaling treatments; $\mathbf{1 . 2 4}$ million francs to the Tobacco Commission of the Provincial Agricultural Committee of Western Flanders for research on the commercial cultivation of tobacco; 1.13 million francs for research on the cultivation, conservation and utilization of medicinal and aromatic plants; and 1.12 million francs to the Committee for Research into Cereal Diseases.

Among smaller grants may be noted those for cotton research $(922,500$ francs), for investigations on the culture of mushrooms (770,000 francs), for research on the sensitization and granulation of photographic emulsions ( 700,000 francs), for scientific and technical research at high pressures $(\mathbf{5 9 5 , 0 0 0}$ francs), for welding research (531,000 francs), for investigations on the specific heat of organic compounds $(360,000$ francs $)$, for microbiological investigations on vinegar manufacture (111,250 francs) and 270,000 francs for investigations on the cultivation of maize in Belgium. The Belgian Centre for Naval Research received 450,000 francs in support of research on thermal and acoustic insulation, while 722,000 francs were granted to the Research Centre of the Belgian Ceramic Industry for investigations on the plasticity of pastes and viscosity of slips used in ceramics and $7 \mathbf{1 2 , 5 0 0}$ francs to the Technical Centre of the Textile Industry for investigations on the oiling of jute fibres. A list of publications relating to assisted researches appearing during the year is included. 